\title{
$\alpha$-Tocopherol Protection against Drought-Induced Damage in Rosmarinus officinalis L. and Melissa officinalis $\mathbf{L}$.
}

\author{
Sergi Munné-Bosch ${ }^{\mathrm{a}, *}$, Karin Schwarz ${ }^{\mathrm{b}}$ and Leonor Alegre ${ }^{\mathrm{a}}$ \\ a Departament de Biologia Vegetal, Facultat de Biologia, Universitat de Barcelona, \\ Av. Diagonal 645, 08028 Barcelona, Spain. Fax: ++34934112842. \\ E-mail: smunne@porthos.bio.ub.es \\ b Institut für Lebensmittelwissenchaft, Universität Hannover, Wunstorfer Strasse 14, \\ 30453 Hannover, Germany \\ * Author for correspondence and reprint requests \\ Z. Naturforsch. 54c, 698-703 (1999); received November 17, 1998/March 20, 1999 \\ $\alpha$-Tocopherol, Photosynthesis, Drought, Rosmarinus officinalis, Melissa officinalis
}

Summer diurnal variations of photosynthesis and $\alpha$-tocopherol content were measured in relation to natural drought in field-grown rosemary (Rosmarinus officinalis L.) and lemon balm (Melissa officinalis L.) plants. During the summer relative water contents (RWC) of $c a$. $40 \%$ in Rosmarinus officinalis and ca. 30\% in Melissa officinalis were attained, indicating severe drought. Both species showed similar diurnal patterns of net $\mathrm{CO}_{2}$ assimilation rates (A) with a wide plateau of maximum photosynthesis at midday in the absence of drought and one peak of maximum photosynthesis early in the morning under drought conditions. Net $\mathrm{CO}_{2}$ assimilation rates decreased by $c a$. $75 \%$ due to drought in both species. Melissa officinalis plants showed a significant decrease in the relative quantum efficiency of PSII photochemistry $\left(\phi_{\mathrm{PSII}}\right)$, ratio of variable to maximum fluorescence yield $\left(F_{\mathrm{v}} / F_{\mathrm{m}}\right)$ and chlorophyll content of leaves by $c a .25 \%$ under drought conditions at midday. In contrast, $\phi_{\text {PSII }}$, $F_{\mathrm{v}} / F_{\mathrm{m}}$ and chlorophyll content remained constant throughout the experiment in $R$. officinalis plants. Although the non-photochemical quenching of chlorophyll fluorescence increased from $c a$. 1.8 to 3 and the $\alpha$-tocopherol content rose fifteen fold in both species in response to drought, only $R$. officinalis plants were able to avoid oxidative damage under drought conditions by the joint increase of carotenoids and $\alpha$-tocopherol.

\section{Introduction}

Chloroplasts are organelles specially exposed to oxygen toxicity, since they function both under high oxygen tensions and in the light. Under drought conditions, limitation of carbon dioxide fixation results in exposure of chloroplasts to excess excitation energy. Mediterranean climate, characterised by the interaction of drought, high light and high temperature during the summer, has led plants to evolve several mechanisms to cope with excess energy. Although photorespiration and energy dissipation as heat by the xanthophyll cycle afford photoprotection to excess energy,

\footnotetext{
Abbreviations: $\alpha$-toc/chl ratio, $\alpha$-tocopherol content per unit of chlorophyll; $\mathrm{A}$, net $\mathrm{CO}_{2}$ assimilation rate; car/chl ratio, total carotenoid content per unit of chlorophyll; DW, dry weight; $F_{\mathrm{v}} / F_{\mathrm{m}}$, variable to maximum fluorescence yield; $g_{\mathrm{s}}$, stomatal conductance; PPFD, photosynthetically active photon flux density; RWC, relative water content; $\phi_{\text {PSII }}$, relative quantum efficiency of photosystem II photochemistry; $\psi$, water potential.
}

photoreduction of oxygen occurs, especially under severe drought conditions, resulting in the formation of activated oxygen species such as singlet oxygen, superoxide radical and lipid peroxides, which can lead to photodamage, chlorophyll degradation, and lipid peroxidation (Smirnoff, 1993; Foyer et al., 1994; Asada, 1996; Osmond et al., 1997).

To counteract the toxicity of activated oxygen species, a highly efficient antioxidative defence system, composed of both non-enzymatic and enzymatic constituents, is present in plant cells. Among the non-enzymatic compounds, tocopherols and carotenoids are responsible for avoiding the negative effects of activated oxygen species in lipid membranes (Smirnoff, 1993; Foyer et al., 1994). $\alpha$-Tocopherol, found in chloroplasts, with one-third located in the envelope and the remaining two-thirds in the thylakoid membranes (Yerin et al., 1984; Wise and Naylor, 1987), is an important antioxidant because it can both deactivate singlet oxygen and terminate lipid peroxidation by 
reducing acyl peroxy radicals (Polle and Rennenberg, 1994). During oxidative stress, the presence of $\alpha$-tocopherol seems to be essential to minimise oxidative damage in plant tissues, but few studies have focused on how drought and daily time variations lead to different endogenous tocopherol levels in plants, and some controversy remains in this field (Fryer, 1992; Schmieden and Wild, 1994).

Diurnal changes in photosynthetic activity measured by leaf gas exchange and chlorophyll fluorescence, as well as changes in $\alpha$-tocopherol during the day were evaluated during Mediterranean summer in $R$. officinalis and $M$. officinalis plants. The relationships between $\alpha$-tocopherol, chlorophyll and carotenoid levels and photodamage in field-grown plants exposed to the interaction of drought, high light and high temperature during the summer were established.

\section{Materials and Methods}

Two year-old plants of rosemary (Rosmarinus officinalis L.) and lemon balm (Melissa officinalis L.) were grown in the experimental fields of the University of Barcelona (Barcelona, NE Spain). Plants were distributed into plots of $4.5 \mathrm{~m}^{2}$ each (16 plants per plot). Twelve plants of each species, of approximately the same size, were chosen for this study. On each plant, one apical shoot was tagged for monitoring the photosynthetic performance during the summer 1997. Plants were grown in Mediterranean climate conditions and received only natural rainfall. Meteorological conditions were recorded throughout the experiment. Photosynthetically active photon flux density (PPFD, $\mu \mathrm{mol} \mathrm{m}^{-2} \mathrm{~s}^{-1}$ ) was measured with a Quantum Sensor (Li-Cor, Lincoln, Nebraska), air temperature $\left(\mathrm{Ta},{ }^{\circ} \mathrm{C}\right)$ and relative humidity $(\mathrm{RH}, \%)$ were measured with a Vaisala thermocouple (Vaisala, Helsinki, Finland), and precipitation $(\mathrm{mm})$ was measured with a standard rain-gauge. Vapour pressure deficit (VPD, KPa) was calculated according to Nobel (1991).

Plant water status was determined before sunrise by measuring the relative water content of leaves calculated as $\mathrm{RWC}(\%)=(\mathrm{FW}-\mathrm{DW}) /$ $(\mathrm{TW}-\mathrm{DW}) \times 100$ where $\mathrm{FW}=$ fresh weight; DW $=$ dry weight, after drying samples to constant weight in an oven at $c a .85^{\circ} \mathrm{C}$; $\mathrm{TW}=$ turgid weight, after rehydrating samples for $24 \mathrm{~h}$.
A LI-6200 portable measuring system (LICOR Inc., Lincoln, Nebraska) was used to measure net $\mathrm{CO}_{2}$ assimilation $(A)$ and stomatal conductance $\left(g_{\mathrm{s}}\right)$ rates at natural incident PPFD throughout the day, using equations developed by von Caemmerer and Farquhar (1981). Steady-state modulated chlorophyll fluorescence of leaves was measured at natural incident PPFD throughout the day using a portable fluorimeter (mini-PAM, Walz, Effeltrich, Germany). The maximum and the relative quantum efficiency of PSII photochemistry were estimated according to Genty et al. (1989) as $_{\text {PSII }}=\left(F_{\mathrm{m}}{ }^{\prime}-F_{\mathrm{s}}\right) / F_{\mathrm{m}}{ }^{\prime}$ and $F_{\mathrm{v}} / F_{\mathrm{m}}=$ $\left(F_{\mathrm{m}}-F_{\mathrm{o}}\right) / F_{\mathrm{m}}$, where $F_{\mathrm{m}}$ and $F_{\mathrm{m}}{ }^{\prime}$ are the maximum fluorescence yields obtained in the dark and lightadapted state, after the application of a saturating pulse of white light; $F_{\mathrm{s}}$ is the fluorescence yield at steady-state photosynthesis obtained a natural incident PPFD; and $F_{\mathrm{O}}$ is the minimum fluorescence yield obtained after dark adaptation for $20 \mathrm{~min}$. The non-photochemical quenching (NPQ) [given by $\left(F_{\mathrm{m}}-F_{\mathrm{m}}{ }^{\prime}\right) / F_{\mathrm{m}}{ }^{\prime}$ ] was estimated according to Bilger and Björkman (1990).

Chlorophyll and carotenoid content of leaves was estimated spectrophotometrically in $80 \%$ (v/v) acetone extracts using the equations described by Lichtenthaler (1987).

For $\alpha$-tocopherol analysis, leaves were collected at predawn and midday, immediately frozen in liquid nitrogen and stored at $-80^{\circ} \mathrm{C}$ until analysis. Leaves were freeze-dried and after grinding, leaf samples $(1 \mathrm{~g})$ were extracted with $5 \mathrm{ml}$ of methanol containing $5 \mathrm{mg}$ citric acid and isoascorbic acid per $100 \mathrm{ml}$ for rosemary or with $5 \mathrm{ml}$ hexane containing 1 ppm BHT for lemon balm, and sonicated for $20 \mathrm{~s}$ (Sonicator Bandelin Sonoplus HD 200 Berlin, Germany; equipped with a MS 73 probe). The extract was centrifuged for $3 \mathrm{~min}$ at $3{ }^{\circ} \mathrm{C}$ and $3000 \mathrm{rpm}$ and the supernatant was transferred into a volumetric flask. The extraction procedure was repeated four times. The supernatants were sucked through a cellulose nitrate filter (Schleicher \& Schuell, Dassel, Germany, pore size $110 \mu \mathrm{m})$, and passed through vacuum distillation, degassed with nitrogen and stored at $-20{ }^{\circ} \mathrm{C}$. Prior to injection, the extract was dissolved in $4 \mathrm{ml}$ acetonitrile and centrifuged for $3 \mathrm{~min}$ at $3{ }^{\circ} \mathrm{C}$ and $3000 \mathrm{rpm}$. $\alpha$-Tocopherol was separated from rosemary on an ODS Hypersil-5 $\mu \mathrm{m}$ column $(250 \times 4 \mathrm{~mm}$, Knauer, Berlin, Germany) using ace- 
tonitrile/distilled water/2 м citric acid (98:2:0.2, $\mathrm{v} / \mathrm{v})$ as an eluant at a flow rate of $1.1 \mathrm{ml} \mathrm{min}^{-1}$, and from lemon balm on a Lichrosorb Si60-5 $\mu \mathrm{m}$ column $(250 \times 4 \mathrm{~mm}$, Knauer, Berlin, Germany) using isooctane/tert-methylbutyl ether $(975: 25, \mathrm{v} / \mathrm{v})$ with a flow-rate of $1.3 \mathrm{ml} \mathrm{min}^{-1}$. UV detection was carried out at $295 \mathrm{~nm}$ (spectralphotometer, Knauer, Berlin, Germany) and fluorescence detection was carried out at an excitation $\lambda$ of $295 \mathrm{~nm}$ and emission at $340 \mathrm{~nm}$ (FS 970 Kratos, Ramsey, NJ, USA). Duplicates were run for each extract. For calibration $\alpha$-tocopherol (Merck, 98.4\% purity) was used.

\section{Results}

The measurement period was typical for the Mediterranean climate characterised by very dry conditions during the summer, disturbed only by some rainfalls, in this case concentrated during the end of June and beginning of July (Fig. 1, upper part). Summer drought caused a decrease in the relative water content (RWC) of leaves from $c a$. $76 \%$ to $42 \%$ in $R$. officinalis and from $c a$. $73 \%$ to

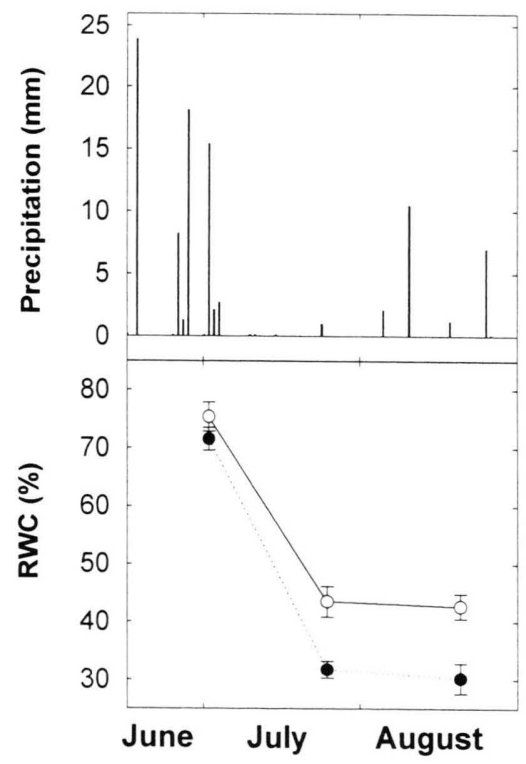

Fig. 1. Daily precipitation at the Experimental Fields of the University of Barcelona (upper part) and predawn relative leaf water content (RWC, lower part) of $R$. officinalis (open symbols) and M. officinalis plants (solid symbols) during summer 1997. Data are the means of six replicates \pm SE.
$30 \%$ in M. officinalis, indicating severe stress during July and August (Fig. 1, lower part).

Fig. 2 shows the diurnal patterns of the environmental conditions, net $\mathrm{CO}_{2}$ assimilation $(A)$ and stomatal conductance $(g \mathrm{~s})$ rates, as well as the diurnal changes in the relative quantum efficiency of PSII photochemistry $\left(\phi_{\text {PSII }}\right)$. From 1 July to $22 \mathrm{Au}$ gust, maximum PPFD decreased from $c a .2000$ to $1800 \mu \mathrm{mol} \mathrm{m}{ }^{-2} \mathrm{~s}^{-1}$, maximum diurnal temperature increased from 22 to $30^{\circ} \mathrm{C}$ and maximum VPD decreased from $3.3 \mathrm{KPa}$ to $2.9 \mathrm{KPa}$. Both species displayed a wide plateau of maximum photosynthesis at midday on 1 July, with maximum photosynthetic rates around $9 \mu \mathrm{mol} \mathrm{m}{ }^{-2} \mathrm{~s}^{-1}$ in $R$. officinalis and $7 \mu \mathrm{mol} \mathrm{m} \mathrm{m}^{-2} \mathrm{~s}^{-1}$ in $M$. officinalis plants. Summer drought caused a depletion of photosynthesis throughout the day and a shift in the maximum peak to early in the morning. Maximum photosynthetic rates decreased to $c a .3 \mu \mathrm{mol} \mathrm{m}^{-2} \mathrm{~s}^{-1}$ on 26 July and $c a .1 .6 \mu \mathrm{mol} \mathrm{m} \mathrm{m}^{-2} \mathrm{~s}^{-1}$ on 22 August in both species. $R$. officinalis showed lower $g$ s rates than $M$. officinalis, even in drought conditions, indicating a higher instantaneous water use efficiency $(A / g s)$. The relative quantum efficiency of PSII photochemistry $\left(\phi_{\mathrm{PSII}}\right)$ decreased during the morning with increases in photosynthetically active photon flux density (PPFD) and then recovered during the afternoon to predawn values. $R$. officinalis maintained the diurnal pattern of $\phi_{\text {PSII }}$ nearly unchanged throughout the experiment with minimum values at midday of $c a$. 0.34 . In contrast, the minimum diurnal $\phi_{\text {PSII }}$ values of M. officinalis plants decreased by ca. $25 \%$ in response to drought (Fig. 2).

Fig. 3 shows the relationship between the degree of water stress expressed by the predawn relative water content (RWC) of leaves and the $F_{\mathrm{v}} / F_{\mathrm{m}}$ ratio, non-photochemical quenching of chlorophyll fluorescence (NPQ), chlorophyll content of leaves, the $\mathrm{Car} / \mathrm{Chl}$ and $\alpha$-toc/Chl ratios at midday, as well as the diurnal variation in the $\alpha$-tocopherol content of leaves (difference between predawn and midday values). Although both species showed similar $F_{\mathrm{v}} / F_{\mathrm{m}}$ values at predawn as indicated by the $\phi_{\text {PSII }}$ values (Fig. 2), only M. officinalis plants showed a clear and significant depletion of the $F_{\mathrm{v}} / F_{\mathrm{m}}$ ratio at midday to $c a$. 0.63 , indicative of photodamage in stressed plants (Fig. 3, upper part). Besides, only this species showed a significant depletion on the total chloro- 


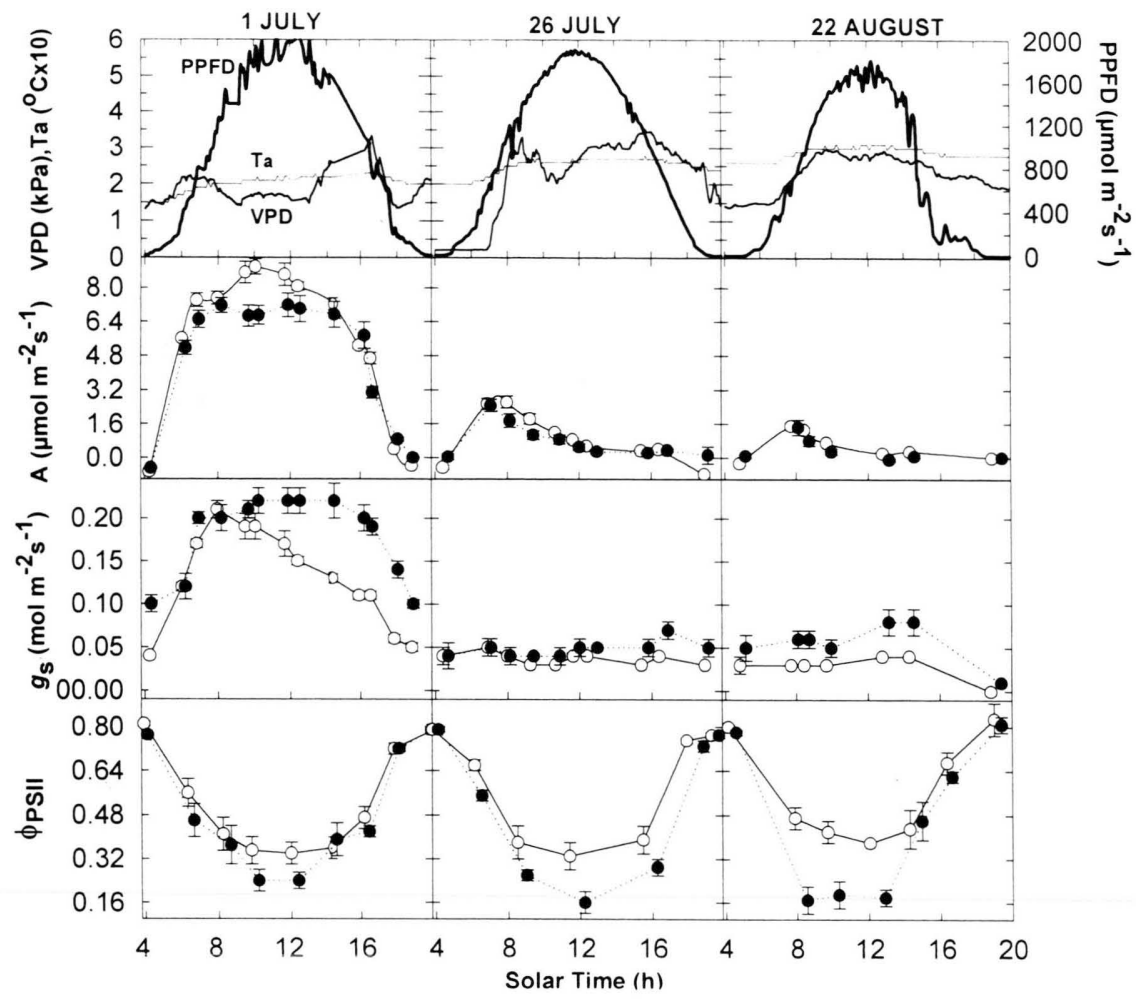

Fig. 2. Diurnal patterns of photosynthetically active photon flux density (PPFD), air temperature $\left(\mathrm{T}_{\mathrm{a}}\right)$ and vapour pressure deficit in the air (VPD) at the experimental fields; and diurnal patterns of net $\mathrm{CO}_{2}$ assimilation rates $(A)$, stomatal conductance (gs) and relative quantum efficiency of photosystem II photochemistry $\left(\phi_{\mathrm{PSI}}\right)$ of $R$. officinalis (open symbols) and $M$. officinalis (solid symbols) during summer 1997. Data are the means of six replicates $\pm \mathrm{SE}$.
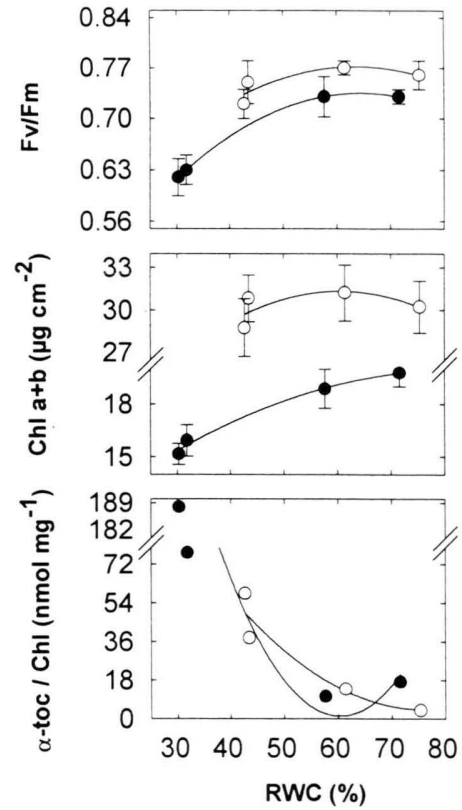

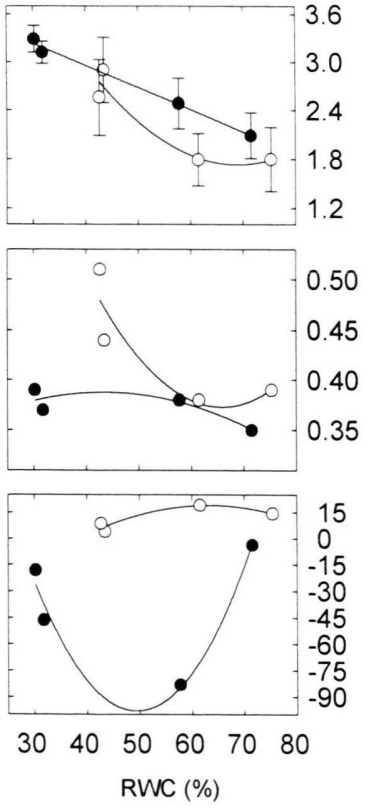

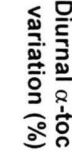

Fig. 3. Relationship between the predawn relative leaf water content (RWC) and the $F_{\mathrm{v}} / F_{\mathrm{m}}$ ratio, non-photochemical quenching of chlorophyll fluorescence (NPQ), chlorophyll content of leaves, $\mathrm{Car} / \mathrm{Chl}$ ratio, and $\alpha$-toc/Chl ratio at midday of $R$. officinalis (open symbols) and $M$. officinalis (solid symbols). The relationship between the RWC and the diurnal variation (difference between predawn and midday) in the $\alpha$-tocopherol content of leaves is also given. Data are the means of six replicates \pm SE. 
phyll content of leaves by ca. $25 \%$ under stress conditions. Although both species showed similar NPQ increases from $c a$. 1.8 to 3 probably associated with excess energy dissipation as heat by the xanthophyll cycle and fifteen-fold increases in the $\alpha$-tocopherol content of leaves per unit of chlorophyll in response to stress, only $R$. officinalis plants increased the Car/Chl ratio by $\mathrm{ca} .30 \%$ and maintained the endogenous $\alpha$-tocopherol levels constant during the day (Fig. 3). In contrast, stressed M. officinalis plants showed $\alpha$-tocopherol decreases during the day between 15 and $75 \%$ depending on the degree of drought, which correspond to a decrease of $c a$. $60 \mu \mathrm{gDW}^{-1}$ both under mild and severe stress conditions. Besides, M. officinalis plants displayed not only diurnal $\alpha$-tocopherol decreases, but also chlorophyll degradation and constant $\mathrm{Car} / \mathrm{Chl}$ levels under severe stress.

\section{Discussion}

Fifteen-fold increases in the $\alpha$-tocopherol content of drought-stressed leaves per unit of chlorophyll for both species suggest an increased electron flux to oxygen when carbon dioxide assimilation was limited, as already showed in plants exposed to other environmental stresses (Fryer et al., 1998). $\alpha$ Tocopherol showed a very similar positive response to drought in both species but the $\alpha$-tocopherol levels in drought-stressed plants were significantly higher in M. officinalis, because this species showed lower RWC values.

R. officinalis and M. officinalis plants followed similar diurnal patterns of carbon dioxide assimilation rates with a decrease by $c a$. $75 \%$ and a displacement of the maximum peak from midday to early in the morning in response to drought, which confirms previous studies that demonstrate that drought not only causes a depletion of $A$ but also a diurnal change in activity (Körner, 1995; Mäkelä et al., 1996). Nevertheless, $R$. officinalis leaves showed a higher instantaneous water use efficiency $(A / g \mathrm{~s})$ than $M$. officinalis, which associated with sclerophylly and shrub form led to a better drought tolerance and higher relative water contents during Mediterranean summer in $R$. officinalis plants (Rundel, 1991; Salleo et al., 1997). The minimum RWC values reached during the summer were significantly higher in $R$. officinalis than in drought-stressed $M$. officinalis plants
$(\mathrm{RWC}=40 \% v$ s. $30 \%)$. This difference in RWC explains the large differences in the $\alpha$-toc/Chl ratio, because of the positive response of $\alpha$-tocopherol to RWC decreases.

The difference in RWC during summer drought could lead to a higher susceptibility to droughtinduced damage in $M$. officinalis plants. Although both species showed increases in NPQ and a similar increase of $\alpha$-tocopherol per unit of chlorophyll in response to drought, only $M$. officinalis showed a significant depletion in the ratio $F_{\mathrm{v}} / F_{\mathrm{m}}$ (indicative of photodamage) and chlorophyll degradation at midday in drought stress conditions. It has been suggested that $\alpha$-tocopherol protects chlorophyll from photooxidation (Wise and Naylor, 1987), thus $\alpha$-tocopherol increases could avoid the degradation of thylakoid constituents in stressed plants of both species. The decrease of $c a$. $60 \mu \mathrm{g} \mathrm{gDW}^{-1}$ of $\alpha$-tocopherol at midday in stressed $M$. officinalis plants may confer protection from oxidative damage, but it may also indicate the susceptibility of this species to suffer from oxidative damage when exposed to high light under severe drought. The protection by $\alpha$-tocopherol in stressed $M$. officinalis plants was not enough to avoid photodamage and chlorophyll degradation under severe stress.

The absence of photodamage and chlorophyll degradation in stressed $R$. officinalis plants, even when exposed to the interaction of stresses during Mediterranean summer may be explained by increases of $c a .30 \%$ in the $\mathrm{Car} / \mathrm{Chl}$ ratio. The parallel increases in the ratios $\mathrm{Car} / \mathrm{Chl}$ and $\alpha$-toc/Chl in response to drought observed only in $R$. officinalis plants confirms the results of Burton and Ingold (1984), who suggested that carotenoids and tocopherols cooperate in the lipid membranes in order to avoid oxidative damage. Thus, the inability to increase the carotenoid content of leaves at the first stages of drought could lead to chlorophyll degradation and photodamage in $M$. officinalis plants, when exposed to the combination of stresses during Mediterranean summer.

\section{Acknowledgements}

The authors acknowledge the grant given to SMB by the University of Barcelona and the financial support to LA received from DGICYT (PB96-1257). 
Asada K. (1996), Radical production and scavenging in the chloroplasts. In: Photosynthesis and the Environment (N. R. Baker, ed.). Kluwer Academic Publishers, Dordrecht, 123-150.

Bilger W. and Björkman O. (1990), Role of the xantophyll cycle in photoprotection elucidated by measurements of light-induced absorbance changes, fluorescence and photosynthesis in leaves of Hedera canariensis. Photosynth. Res. 25, 173-185.

Burton G. W. and Ingold K. U. (1984), $\beta$-Carotene: an unusual type of lipid antioxidant. Science 224, 569573.

Foyer C. H., Descourvières P. and Kunert K. J. (1994), Protection against oxygen radicals: an important defence mechanism studied in transgenic plants. Plant Cell Environ. 17, 507- 523.

Fryer M. J. (1992), The antioxidant effects of thylakoid vitamin E ( $\alpha$-tocopherol). Plant Cell Environ. 15, $381-392$

Fryer M. J., Andrews J. R., Oxborough K., Blowers D. A. and Baker N. R. (1998), Relationship between $\mathrm{CO}_{2}$ assimilation, photosynthetic electron transport, and active $\mathrm{O}_{2}$ metabolism in leaves of maize in the field during periods of low temperature. Plant Physiol. 116, $571-580$.

Genty B., Briantais J. M. and Baker N. R. (1989), The relationship between the quantum yield of photosynthetic electron transport and quenching of chlorophyll fluorescence. Biochim. Biophys. Acta 990, 87-92.

Körner C. (1995), Leaf diffusive conductances in the major vegetation types of the globe. In: Ecophysiology of Photosynthesis (E. D. Schulze and M. M. Caldwell, eds.). Springer, Berlin, 463-490.

Lichtenthaler H. K. (1987), Chlorophylls and carotenoids: pigments of photosynthetic biomembranes. Meth. Enzym. 148, 350-382.
Mäkëla A., Berninger F. and Hari P. (1996), Optimal control of gas exchange during drought: theoretical analysis. Ann. Bot. 77, 461-467.

Nobel P. S. (1991), Physicochemical and Environmental Plant Physiology. Academic Press, San Diego.

Osmond B., Badger M., Maxwell K., Björkman O. and Leegod R. (1997), Too many photons: photorespiration, photoinhibition and photooxidation. Trends Plant Science 2, 119-120.

Polle A. and Rennenberg H. (1994), Photooxidative stress in trees. In: Causes of Photoxidative Stress and Amelioration of Defence Systems in Plants (C. H. Foyer and P. M. Mullineaux, eds.). CRC Press, Boca Raton, 199-218.

Rundel P. W. (1991), Shrub life-forms. In: Response of Plants to Multiple Stresses (H. A. Mooney, W. E. Winner and E. J. Pell, eds.). Academic Press, San Diego, $345-370$.

Salleo S., Nardini A. and Lo Gullo M. A. (1997), Is sclerophylly of Mediterranean evergreens an adaptation to drought? New Phytol. 135, 603-612.

Schmieden U. and Wild A. (1994), Changes in levels of $\alpha$-tocopherol and ascorbate in spruce needles of three low mountain sites exposed to $\mathrm{Mg}^{2+}$-deficiency and ozone. Z. Naturforsch. 49c, 171-180.

Smirnoff N. (1993), Tansley Review No. 52. The role of active oxygen in the response of plants to water deficit and desiccation. New Phytol. 125, 27-58.

von Caemmerer S. and Farquhar G. D. (1981), Some relations between the biochemistry of photosynthesis and the gas exchange of leaves. Planta 153, 376-387.

Wise R. R. and Naylor A. W. (1987), Chilling enhanced photooxidation. Plant Physiol. 83, 278-282.

Yerin A. N., Kormanovskii Y. and Ivanov I. I. (1984), Localisation of $\alpha$-tocopherol in chloroplasts. Biophysics 29, 363-364. 